\title{
MOHAMMAD-ARIF (Aminah), Salam America. L'islam indien en diaspora
}

Paris, CNRS Éditions, 2000, 392 p., (bibliogr., tableaux, illustr., cartes, index) (coll. « Monde indien. Sciences Sociales $15^{\mathrm{e}}-20^{\mathrm{e}}$ siècle »)

\section{Malika Zeghal}

\section{(2) OpenEdition}

\section{Journals}

Édition électronique

URL : http://journals.openedition.org/assr/20800

DOI : $10.4000 /$ assr. 20800

ISSN : $1777-5825$

Éditeur

Éditions de l'EHESS

\section{Édition imprimée}

Date de publication : 1 juin 2001

Pagination : 101-102

ISBN : 2-222-96704-X

ISSN : 0335-5985

Référence électronique

Malika Zeghal, "MOHAMMAD-ARIF (Aminah), Salam America. L'islam indien en diaspora », Archives de sciences sociales des religions [En ligne], 114 | avril-juin 2001, document 114.31, mis en ligne le 19 août 2009, consulté le 21 septembre 2020. URL : http://journals.openedition.org/assr/20800 ; DOI : https:// doi.org/10.4000/assr.20800

Ce document a été généré automatiquement le 21 septembre 2020

(c) Archives de sciences sociales des religions 


\section{MOHAMMAD-ARIF (Aminah), Salam America. L'islam indien en diaspora}

Paris, CNRS Éditions, 2000, 392 p., (bibliogr., tableaux, illustr., cartes, index) (coll. « Monde indien. Sciences Sociales $15^{\mathrm{e}}-20^{\mathrm{e}}$ siècle »)

\section{Malika Zeghal}

\section{RÉFÉRENCE}

MOHAMMAD-ARIF (Aminah), Salam America. L'islam indien en diaspora, Paris, CNRS

Éditions, 2000, 392 p., (bibliogr., tableaux, illustr., cartes, index) (coll. « Monde indien.

Sciences Sociales $15^{\mathrm{e}}-20^{\mathrm{e}}$ siècle $\left.»\right)$

1 Issu d'une thèse de doctorat soutenue à l'Ecole des Hautes Études en Sciences Sociales, Salam America traite des musulmans de l'Asie du Sud implantés à New York des années 1960 à nos jours. Se fondant sur plus d'une centaine d'entretiens et sur l'observation directe de familles sud-asiatiques installées aux États-Unis, l'auteur montre la diversité ethnique de la population qu'elle étudie en retraçant de manière précise et rigoureuse l'histoire de l'islam dans le sous-continent indien, et celle des premières vagues d'émigration aux États-Unis jusque dans les années 1960, soulignant notamment le niveau élevé d'éducation des migrants de l'après-guerre, et la prospérité de leur communauté aux États-Unis, qui en fait une diaspora bien spécifique si on la compare à d'autres groupes migrants musulmans dans la période contemporaine.

Elle détaille ensuite les pratiques religieuses de ces migrants, des interdits alimentaires aux pratiques vestimentaires, en passant par les aspects économiques ou les rites de passage. En reprenant des récits de vie, en citant les entretiens très riches qu'elle a pu obtenir sur le terrain, elle décrit l'adaptation aux pratiques du pays d'accueil, et les difficultés éprouvées par la seconde génération, prise entre les attentes parentales et les perspectives d'intégration à la société américaine. Elle montre que les parents s'efforcent d'intégrer leurs enfants à la société dans laquelle ils vivent, en particulier par l'éducation sans abandonner l'islam comme fondement de leur culture identitaire. 
Elle construit d'ailleurs tout au long de son ouvrage une comparaison avec les musulmans de France insérés dans une «logique de confrontation» (p. 156) avec la culture du pays d'accueil, alors que - en grande partie grâce à leur situation socioéconomique d'origine, à leur réussite matérielle et à leur niveau d'instruction - les musulmans indo-pakistanais ont pu s'intégrer plus facilement et apparaître généralement comme une communauté « modèle ».

3 L'A. montre aussi que le processus de migration a abouti à une "redéfinition de l'islam». Cette redéfinition s'est produite à travers la création d'institutions diversifiées, qui se sont formées sur le modèle de la congrégation, profitant du pluralisme religieux américain, et offrant à chaque type de population le genre de produit religieux qui correspondait à ses besoins. Elle en montre la diversité, en présentant diverses études de cas qui mettent en avant les affiliations ethniques, mais prouvent aussi que les institutions ont été largement adaptées au contexte américain. Le sermon en anglais, les réunions à la mosquée le dimanche au lieu du vendredi, l'organisation des cérémonies de mariage au sein même de la mosquée en mêlant hommes et femmes, l'introduction du cercueil aux funérailles montrent que la migration, et plus largement les phénomènes de globalisation, s'accompagnent d'une hybridation des représentations et des pratiques. De plus, la religion des migrants s'objectifie, se rationalise. Elle devient objet d'attention et de débat et non simple pratique machinale. Elle sert ainsi d'instrument d'affirmation identitaire et de rationalisation du réel par le regard réflexif, la «redécouverte de la norme ». L'A. montre avec finesse ce processus de rationalisation, notamment en rapportant les discours de justification du port du voile par des migrantes qu'elle a interrogées (pp. 95-97). Plus généralement: «L'idée que le processus d'émigration a permis une compréhension meilleure de sa religion est en effet constamment soulignée par les immigrants sud-asiatiques qui opposent leur propre interprétation de l'islam en terre d'immigration à celle qui était la leur précédemment » (p. 98).

Participant à cette redéfinition de l'islam, ou plus rarement essayant de la contrer pour donner forme à un islam plus orthodoxe, des organisations musulmanes transnationales tentent de mobiliser sur des modes très divers les musulmans sud-asiatiques de New York, en particulier à travers le travail de prédication ( $\left.d a^{\prime} w a\right)$. L'A. montre aussi que l'islam des migrants de l'Asie du Sud tend de plus en plus à dépasser les clivages ethniques, non pas par la constitution d'institutions particulières ou spécifiques à la communauté musulmane, mais par la participation à des processus définis par la société américaine elle-même et qui permettent de s'intégrer en tant que "minorité » (à travers la pratique de la parade, l'utilisation de l'internet, ou la pratique du lobbying). Si ce biais permet de transcender timidement les divisions ethniques au sein de la communauté musulmane, il «ethnicise » paradoxalement les musulmans aux yeux du reste de la société américaine.

5 Salant America montre que l'affirmation identitaire par le religieux de la part des migrants ne constitue pas nécessairement un obstacle à leur intégration aux États-Unis. Celle-ci s'affirme - au sein de la société américaine - à travers leur réussite économique et sociale. L'ouvrage a le grand mérite d'avoir construit une ébauche de comparaison avec la communauté musulmane en France, permettant ainsi de reposer en filigrane la question du rôle de l'identité religieuse dans son intégration. 